\title{
Anxiety, Self-Efficacy, and College Exam Grades
}

\author{
Jennifer Barrows ${ }^{1}$, Samantha Dunn ${ }^{1}$, Carrie A. Lloyd ${ }^{2, *}$ \\ ${ }^{1}$ Butler University Conference, April, 2013, in Indianapolis, Huntington University \\ ${ }^{2}$ Department of Psychology, Huntington University, 2303 College Avenue, Huntington, IN 46750 \\ *Corresponding Author: clloyd@huntington.edu
}

Copyright (C) 2013 Horizon Research Publishing All rights reserved.

\begin{abstract}
A student's level of self-efficacy and test anxiety directly impacts their academic success (Abdi, Bageri, Shoghi, Goodarzi, \& Hosseinzadeh, 2012; Hassanzadeh, Ebrahimi, \& Mahdinejad, 2012). When a student doubts themself and their own ability to test well, the students' sole focus becomes worrying about poor grades and cannot focus on academics (Bandura, 1993). But, little is understood about how test-anxiety and self-efficacy affect short-term success in the classroom. Specifically, how test anxiety and level of self-efficacy directly preceding an exam will affect the exam score. Pre-and post-questionnaires assessing anxiety and self-efficacy immediately before and after a single college exam was completed by 110 college students and exam grades were obtained from the instructor. Results showed a strong relationship between both test anxiety and exam grades, and self-efficacy and exam grades. Further, multiple linear regression analyses showed that exam grade could be predicted by test anxiety and self-efficacy level, and that self-efficacy moderated the effects of anxiety.
\end{abstract}

Keywords College Exams, Test Anxiety, College Students, Academic Performance, Self-Efficacy

\section{Introduction}

Test anxiety negatively affects students; more so if the anxiety is dealt with in an unhealthy manner and extends over a long period of time. Hill and Wigfield (1984) approximate that 10 million primary and secondary students' test anxiety causes decreased test performance. Test anxiety is a multi-dimensional phenomenon that involves worry, emotionality, and behavioral reply to being preoccupied by the possible negative outcome of academic scores (Chapell, Blanding, Silverstein, Takahashi, Newman, Gubi, \& McCann, 2005; Mulkey \& O' Neil, 1999). Students' level of test anxiety can cause a variety of negative outcomes, mainly low academic scores. But, overall self-efficacy may moderate this effect.

Test anxiety is detrimental to overall academic success. Chapell et al. (2005) asked 5,551 participants to complete the
Test Anxiety Inventory (TAI; Spielberger, 1980), report their current cumulative GPA, and complete a self-report scale detailing their grades (Dornbusch, Ritter, Leiderman, Roberts, \& Fraleigh, 1987). The authors found a one-third letter grade difference between undergraduates with high test anxiety and low test anxiety (Chapell et al., 2005). So, in addition to typically discussed measures of academic performance (e.g., intelligence, capability, study habits), test anxiety also plays a role in whether or not students perform well in academics.

Davis et al. (2008) and Pintrich and De Groot (1990) support Chapell et al.'s (2005) results. Davis et al. studied 2,215 first-year college students (56\% female, $44 \%$ male); asking students to complete the Cognitive-Appraising Processing subscales of the Emotional Regulation during Test Taking Scale (Schutz et al., 2004) and the Test Anxiety Scale of the Learning and Study Strategies Inventory (Weinstein et al., 1987). There was a strong correlation between test anxiety and SAT and general quantitative scores. The cluster of students who had high test anxiety had difficulty coping with the stress of the tests which resulted in lower standardized test scores. Pintrich and De Groot's (1990) findings report that test anxiety negatively impacts memory and the ability to retrieve information from memory storage, and thus makes it difficult to retrieve information when needed on exam to correctly answer questions.

More recent studies show the same outcome. In the first study, Lang and Lang (2010) studied 219 secondary and vocational school students (122 female, 97 male) and 232 students (132 female, 100 male) secondary students in a second study. Students in the first study completed the Test Anxiety Inventory (TAI-G; Hodapp, Laux, \& Spielberger, 1982) and in the second study, the students completed a test performance measure in addition to two questionnaires asking about the extent to which they were engaged with the assignment given to them (Rheinberg \& Vollmeyer, 2003) and the extent to which they were worrying (Rheinberg \& Vollmeyer, 2003). Both groups showed a decrease in test performance, regardless of measure, with increased worry about the test. Similarly, Abdi, Bageri, Shoghi, Goodarzi, \& Hosseinzadeh (2012) tested 127 randomly chosen high school students with the Spielberger test anxiety scale. Correlations and regression analyses found a relationship 
between test anxiety and overall grade point average. Hassanzadeh, Ebrahimi, and Mahdinejad's (2012) study added to this literature in that the students' level of test anxiety can cause the students' academic performance to suffer even more depending on the length of time they suffer from test anxiety. These results show that test anxiety inhibit students' ability to focus on academics which negatively influences grades.

Worry and emotionality are two different ways that the body naturally responds to test anxiety. Too much worry negatively affects performance, but self-efficacy might moderate this influence. Self-efficacy influences people's belief about their own capabilities, which has been shown to enhance students' academic performance (Bandura, 1993; Mulkey \& O'Neil, 1999). When students are plagued with worry they tend to be distracted or preoccupied with various stressors that burden them, such as the outcome (Cohen et al., 2008; Liebert \& Morris, 1967). Thus, it seems reasonable to conclude that students with high self-efficacy would not worry as much about the test results. Mulkey and O'Neil (1999) asked 610 males over the age of 18 to take the Novell NetWare 4.1 examination to determine the effects of their worry and self-efficacy. Individuals who were master's degree students performed well because they stated a belief in their own ability to accomplish the examination given to them, but the opposite was true for most undergraduate students. Abdi et al. (2012) find similar results in their study with high school students. A significant correlation existed between self-efficacy and overall grade points. Regression analyses further showed that self-efficacy could accurately predict academic performance. Emotional responses such as anxiety are the body's physiological response directed by the autonomic nervous system which increases heart rate and sweating in reaction to a stressful situation such as an exam (Cohen et al., 2008; Mulkey \& O’Neil, 1999). Individuals who have high self-efficacy, or confidence in their own skills and abilities, seem to be able to control this physiological response from affecting them negatively (Bandura, 1986, 1997).

Empirical evidence also supports the relationship between self-efficacy and test-anxiety and academic achievement within specific academic disciplines. For instance, Yildirim (2012) found that high math self-efficacy is positively related to math achievement and high test-anxiety is negatively related to math achievement. Using Structural Equation Modeling analyzing data of 297 undergraduate engineering students, Hsieh, Sullivan, Sass, and Guerra (2012) found that self-efficacy and test anxiety both predicted students' final grades in a math class. Literacy self-efficacy related to literacy competence scores (Bostock \& Boon, 2012) and teaching self-efficacy tools and management of test-anxiety to students in Science and Technology courses increased their grade in those courses more than students who were taught only with standard teaching methods (Gencosman \& Dogru, 2012).

Individuals who do not perceive themselves as competent lose motivation to complete hard tasks and instead seem to focus on possible negative outcomes. Students with low levels of self-efficacy focus their attention on the many ways their possible failure on a task could jeopardize areas of their lives (Bandura, 1993). Those with low self-efficacy also do not seek out opportunities to gain the knowledge or skills necessary to make success more likely, including building self-confidence in their own abilities. One reason for this is that these individuals see themselves as unintelligent when asked to put forth a great deal of effort. Students who perform poorly may see difficult experiences as threats and attribute the results to their own negative internal characteristics. This perceived incompetence increases test anxiety and typically causes an even greater negative effect on performance. But, high self-efficacy can do the opposite.

Students with high levels of self-efficacy imagine how they can succeed and they trust in their own abilities (Bandura, 1993). Nelson and Knight's (2010) study showed that students can avoid negative outcomes of test anxiety by thinking of past achievements, which will build courage and endurance, and in turn will increase their self-efficacy. Those who focus on the area that they are skilled at, cope better and have lower anxiety. Positive thinking techniques can transfer into the classroom and help students excel in academic achievement as well. Students who perceive themselves as being competent will more likely strive to learn how to do better on challenging tasks such as exams. Those with high levels of self-efficacy show lower levels of test anxiety, possibly because they believe in themselves and are able to imagine a successful outcome.

Current literature (e.g., Abdi et al., 2012; Adewuyi, Taiwo, \& Olley, 2012) has studied how overall grade point averages and standardized tests are affected by long-term test anxiety and self-efficacy in general by giving test anxiety and self-efficacy measures and comparing the scores to overall GPA as well as overall grades in various disciplines, but have not looked at the effects of short-term test anxiety and self-efficacy directly before an exam and comparing the direct effect of that anxiety and self-efficacy on the exam score. Because of the plethora of evidence showing how long-term test anxiety and low self-efficacy negatively affects academic performance, the current researchers hypothesized that those with low self-efficacy and high test anxiety would also have a lower single test grade than those with high self-efficacy and low test anxiety. By examining test-anxiety and self-efficacy within single, short-term situations, the effects may be more manageable. Also, test anxiety and self-efficacy both play a role in influencing students' academic performance, but high levels of test anxiety will typically negatively influence students' ability to do well academically while high levels of self-efficacy typically builds courage and confidence in students' own ability to complete hard tasks and thus positively influences academics. Because of this established relationship between test anxiety and academic achievement and self-efficacy and academic achievement, the second hypothesis was that self-efficacy would moderate the effect test anxiety on academic achievement. 


\section{Methodology}

\subsection{Participants}

The current study was conducted at a small university in the rural Midwest. A total of 110 students (37 male, 73 female) participated in the study. The age of the participants ranged between 18 and 23 years old $(M=20.22, S D=1.42)$. The researchers randomly chose majors from the registration class lists and included one class from each of the main departments (i.e., Psychology, Sociology, Communication, Business, English, Music, and History).

\subsection{Measures}

The researchers used a previously validated questionnaire, Motivated Strategies for Learning Questionnaire (MSLQ), which was used as both the pre- and post-questionnaire. The questionnaire was composed of 13 questions split into two sections: one measuring self-efficacy and the other measuring test anxiety (Pintrich \& De Groot, 1990). The questionnaires (pre- and post-) were given out individually to each participant during class-time. The pre-questionnaire was given out three days before the test and an identical questionnaire directly after the test was taken. A 7-point Likert scale $(1=$ not at all true to $7=$ very true of me $)$ was used to rate the students' level of test anxiety and self-efficacy. An example of one of the questions for self-efficacy included: "I'm certain I can understand the ideas taught in this course." An example of one of the questions for test anxiety included: "I am so nervous during a test that I cannot remember facts I have learned." The single test grade was collected from the professor, and then the single test grade was compared to the student's test anxiety and self-efficacy answers on the preand post-questionnaires.

\subsection{Procedure}

The researchers first conducted a pilot study which included 15 students to test the operations of the study. Professors who consented to participate in the study were randomly selected from seven different departments (Psychology, Sociology, Communication, Business, English, Music, and History). These seven professors were asked to allow the researchers to come into their classroom and solicit volunteers to participate in the study by taking a pre-and post-questionnaire before and after the classes' scheduled class exam. A consent form was given out to each of the students immediately before the pre-questionnaire. The consent form allowed the researchers to receive each student's single test grades after the exam. The students that participated in the study were given an incentive of having the chance to win a $\$ 25$ gift card.

\section{Results}

The Paired samples $t$-tests determined several significant mean differences for the participants' single test grades between the pre-and post- test answers. The next part of this section addresses the relationship between short-term test-anxiety, self-efficacy, and the single exam grade. A bivariate linear regression then analyzed the main research question being whether test-anxiety and/or self-efficacy predicts, and how accurately did each predict, a single exam grade. The bivariate linear regression was also assessed to see whether self-efficacy moderates test-anxiety. The results support the hypothesis that, on average, participants had high self-efficacy and low test anxiety, and those that had low self-efficacy and high test anxiety had lower exam grades than those with high self-efficacy and low test anxiety. Contrary to the hypothesis, self-efficacy was not found to be a moderator of test-anxiety for a single exam.

Descriptive statistics assessed participants' pre-and post-questionnaires and test grade. As expected, results for the pre-questionnaire showed more test anxiety $(M=13.30$, $S D=5.58)$ in comparison to the post-questionnaire $(M=$ $12.70, S D=5.62$ ) for test anxiety. Female participants' results showed higher test anxiety before the test $(M=15.40$, $S D=5.75)$ in comparison to the mean after the test $(M=$ 14.30, $S D=6.02$ ). Male participants' results on the pre-questionnaire showed that they had higher self-efficacy before the test $(M=48.05, S D=7.10)$ in comparison to after the test $(M=46.27, S D=7.35)$. Female participants' results also showed higher self-efficacy before the test $(M=48.32$, $S D=7.42)$ in comparison to after the test $(M=46.90, S D=$ $8.27)$. Male participants' had lower average test grades $(M=$ $4.05, S D=1.05)$ than female participants' test grades $(M=$ $4.08, S D=1.09$ ).

Paired samples $t$-tests determined whether or not the participants' means between the pre- and the post- test anxiety as well as pre- and the post- self-efficacy were significantly different. The mean difference between the students' pre- $(M=14.69, S D=5.76)$ and post- $(M=13.76$, $S D=5.91)$ test anxiety was significant, $t(2.67)=2.67, p$ $=.009$. The mean difference between the students' pre- $(M=$ 48.23, $S D=7.28)$ and post- $(M=46.68, S D=7.94)$ self-efficacy was also significant, $t(109)=3.28, p=0.001$.

Multiple analyses of variance (MANOVA) were then analyzed to determine whether or not there was a significant mean difference between each of the students' single test grades (A, B, C, D, or F) and pre-and post- test anxiety and self-efficacy. There was a significant mean difference for the letter grade on the exam and their self-efficacy before the exam, $F(4,105)=3.16, p<.05$. A follow-up one-way ANOVA did not show a significant mean difference for type of letter grade on the exam (A, B, C, D, or F) and test anxiety. (see Table 1 for means and standard deviations) 
Table 1. MANOVA Results for Test Grades

\begin{tabular}{cccccccccccc}
\hline & \multicolumn{2}{c}{ A } & \multicolumn{2}{c}{ B } & \multicolumn{2}{c}{ C } & \multicolumn{2}{c}{ D } & \multicolumn{2}{c}{ F } \\
\cline { 2 - 11 } & $M$ & $S D$ & $M$ & $S D$ & $M$ & $S D$ & $M$ & $S D$ & $M$ & $S D$ \\
\hline Pre-Test Anxiety & 14.02 & 6.06 & 14.50 & 5.62 & 16.12 & 5.40 & 13.83 & 5.78 & 19.75 & 1.71 \\
\hline Post-Test Anxiety & 13.49 & 5.80 & 13.68 & 5.87 & 13.24 & 5.63 & 13.50 & 7.04 & 20.50 & 6.14 \\
\hline Pre-Self-Efficacy & 50.86 & 7.83 & 46.47 & 6.73 & 45.82 & 5.13 & 45.50 & 5.65 & 45.25 & 6.80 \\
\hline Post-Self-Efficacy & 50.06 & 7.72 & 44.56 & 7.66 & 44.06 & 6.61 & 44.50 & 5.13 & 37.75 & 4.86 \\
\hline
\end{tabular}

Pearson correlation coefficients also found significant relationships between the pre- and the post-questionnaire results for test anxiety, self-efficacy, and the students' single test grades. The analyses showed a significant negative correlation between the students' pre- test anxiety and exam score $(r=-.16, p<.05)$. There was also a significant positive correlation between the students' pre-test self-efficacy and exam score $(r=.28, p=0.002)$. (see Table 2 for means and standard deviations)

Table 2. Descriptive Statistics for Pre- and Post-Test Anxiety and Self-Efficacy

\begin{tabular}{ccc}
\hline & $M$ & $S D$ \\
\hline Pre-Test Anxiety & 14.69 & 5.76 \\
Post-Test Anxiety & 13.76 & 5.91 \\
Pre-Self-Efficacy & 48.23 & 7.28 \\
Post-Self-Efficacy & 46.68 & 7.94 \\
\hline
\end{tabular}

A multiple regression analysis was then conducted to evaluate how well the anxiety and self-efficacy measures predicted the single exam score. The predictors were anxiety and self-efficacy, while the criterion variable was the exam score. The results of this analysis indicated that test anxiety and self-efficacy accounted for a significant amount of the exam score variability, $R^{2}=.08, F(2,107)=4.81, p=.01$, indicating that students with low self-efficacy who have more test anxiety tended to have lower scores on the exam.

A second multiple regression analysis was conducted to evaluate whether self-efficacy predicted the exam score over and above test-anxiety. The self-efficacy measure did not account for a significant proportion of the exam score variance after controlling for the effects of test-anxiety, $R^{2}$ change $=.05, F(8,99)=.69, p=.70$. These results suggest that self-efficacy does not moderate the effect of test anxiety. Regardless of self-efficacy levels, if students have high test anxiety they were more likely to have a lower exam grade.

\section{Discussion}

The results supported the hypothesis that higher levels of test anxiety directly before an exam will negatively affect a student's exam grade. The results did not support the researchers' hypothesis that self-efficacy may act as a moderator to the test-anxiety.

Similar to previous research (Pintrich \& De Groot, 1990) we found a relationship between self-efficacy and a student's academic performance. The more self-efficacy a student has the more they will feel they will do well and this will help them do well on an exam. The current researcher's extended Pintrich and De Groot's (1990) results, that there is a relationship between overall self-efficacy and academic achievement, by showing a relationship between participants' self-efficacy directly before a single exam and their consequent exam grade. Obviously studying increases test performance, but this study shows that studying is not the only factor--the students' perception of their academic performance, or confidence in doing well, also has a considerable effect on the outcome.

We also found a relationship between test anxiety and participants' test grade. Previous literature (e.g., Chapell et al., 2005) reported a one-third letter overall grade difference between undergraduates with high test anxiety and undergraduates with low test anxiety. The current study's results found a similar effect within a single exam, not only overall GPA. The level of test anxiety directly before an exam actually predicted the student's exam grade.

The present study's results supported previous literature (e.g., Davis et al., 2008) showing a strong relationship between self-efficacy and test anxiety. Davis et al. (2008) found a strong relationship between test problem efficacy and overall test anxiety. The current researchers extended this discovery by showing a strong relationship between participants' specific test anxiety and self-efficacy.

Because of these previous studies showing that self-efficacy and test anxiety affected academic grade point averages and that there was a negative relationship between self-efficacy and test anxiety, we predicted that there would not only be a relationship between self-efficacy, test anxiety, and single test grades, but that self-efficacy may even moderate the negative effects of test anxiety. But, although our results did not support the hypothesis that self-efficacy moderates test anxiety, our results may have even greater implications. Test anxiety may be too detrimental to have a moderating variable, even high self-efficacy. Future research should look into other possible moderators of test anxiety on single exams. Future research should also look further into how students can lower their anxiety before each exam 
because of the negative effect test anxiety has on not only long-term academic success, but on each exam score. If short-term anxiety can be lowered, this will inevitably lessen the effect test anxiety has on overall academic performance.

One limitation of this study may have been the difficulty level of the tests across disciplines. Although this should have been accounted for by the students' answers to the preand post- test anxiety and self-efficacy questions, perhaps the various levels of difficulty of each exam or subject may have influenced the outcome.

\section{Conclusion}

Empirical evidence supports the relationship between self-efficacy, test anxiety, and overall academic success, and our results further this literature in showing a relationship between self-efficacy, test anxiety, and single test grades. Also, we found that self-efficacy does not moderate test anxiety or the test grade, which has interesting implications for future researchers to discover if a moderator does exist as well as how to lower test anxiety immediately before an exam.

\section{REFERENCES}

[1] Abdi, H. M., Bageri, S., Shoghi, S., Goodarzi, Sh., \& Hosseinzadeh, A. (2012). The role of metacognitive and self-efficacy beliefs in students' test anxiety and academic achievement. Australian Journal of Basic and Applied Sciences, 6(12), 418-422.

[2] Adewuyi, T. O., Taiwo, O. K., \& Olley, B. O. (2012). Influence of examination anxiety and self-efficacy on academic performance among secondary school students. IFE Psychologia, 20(2), 60-68.

[3] Bandura, A. (1993). Perceived self-efficacy in cognitive development and functioning. Educational Psychologist, 28(2), 117-148.

[4] Bostock, L., \& Boon, H. (2012). Pre-service teachers' literacy self-efficacy and literacy competence. Australian and International Journal of Rural Education, 22(1), 19-37.

[5] Chapell, M. S., Blanding, Z. B., Silverstein, M. E., Takahashi, M., Newman, B., Gubi, A., \&McCann, N. (2005). Test anxiety and academic performance in undergraduate and graduate students. Journal of Educational Psychology, 97(2), 268-274. doi:10.1037/0022-0663.97.2.268

[6] Cohen, M., Ben-Zur, H., \& Rosenfeld, M. J. (2008). Sense of coherence, coping strategies, and test anxiety as predictors of test performance among college students. International
Journal of Stress Management, 15(3), 289-303. doi:10.1037/ 1072-5245.15.3.289

[7] Davis, H. A., DiStefano, C., \& Schutz, P. A. (2008). Identifying patterns of appraising tests in first-year college students: Implications for anxiety and emotion regulation during test taking. Journal of Educational Psychology, 100(4), 942-960. doi:10.1037/a0013096

[8] Gencosman, T., \& Dogru, M. (2012). Effect of student teams-achievement division's technique used in science and technology education on self-efficacy, test anxiety, and academic achievement. Journal of Baltic Science Education, 11(1), 43-54.

[9] Hassanzadeh, R., Ebrahimi, S., \& Mahdinejad, G. (2012). Studying test anxiety and its relationship with self-efficacy, metacognitive beliefs and some effective predictable variables. European Journal of Social Services, 30(4), 511-522.

[10] Hill, K. T., \& Wigfield, A. (1984). Test anxiety: A major educational problem and what can be done about it. Elementary School Journal, 85, 105-126.

[11] Hsieh, P., Sullivan, J. R., Sass, D. A., \& Guerra, N. S. (2012). Undergraduate engineering students' beliefs, coping strategies, and academic performance: An evaluation of theoretical models. The Journal of Experimental Education, 80(2), 196-218. doi:10.1080/00220973.2011.596853

[12] Lang, J. W. B., \& Lang, J. (2010). Priming competence diminishes the link between cognitive test anxiety and test performance: Implications for the interpretation of test scores. Psychological Science, 21(6), 811-819. doi:10.1177/0956797610369492

[13] Liebert, R. M., \& Morris, L. W. (1967). Cognitive and emotional components of test anxiety: A distinction and some initial data. Psychological Reports, 20, 975-978.

[14] Mulkey, J. R., \& O’Neil, H. F., Jr. (1999). The effects of test item format on self-efficacy and worry during high-stakes computer-based certification examination. Computers in Human Behavior, 15(3-4), 495-506.

[15] Nelson, D.W., \& Knight, A.E. (2010). The power of positive recollections: Reducing test anxiety and enhancing college student efficacy and performance. Journal of Applied Social Psychology, 40(3), 732-745.

[16] Pintrich, P.R., \& De Groot, E.V. (1990). Motivational and self-regulated learning components of classroom academic performance. Journal of Educational Psychology, 82(1), $33-40$.

[17] Pintrich, P. R., \& De Groot, E. V. (1990). PsycTESTS: Motivated strategies for learning questionnaire [Database record]. Published instrument.

[18] Yildirium, S. (2012) Teacher support, motivation, learning strategy use, and achievement: A multilevel mediation model. The Journal of Experimental Education, 80(2), 150-172. 